\title{
ANN Model of Border Regions Development: Approach of Closed Systems
}

\author{
Yurii Koroliuk \\ Department of Economic Cybernetics and International Economic Relations, Chernivtsi Institute of Trade and \\ Economics KNUTE, Chernivtsi, Ukraine \\ E-mail: yu_kor@ukr.net \\ Valentyn Hryhorenko \\ Ukrainian Leadership Academy, Lviv, Ukraine \\ E-mail: Vallenymeta@gmail.com
}

Received: 29 June 2019; Accepted: 12 August 2019; Published: 08 September 2019

\begin{abstract}
In this article we have suggested a new method of regional systems study that is based on model environmental influences isolation on their parameters dynamics. The presented model deepens greatly the investigation process of complex systems and allows defining clearly its functioning peculiarities without significant reduction in number of system characteristics as if we have simple technical or physical objects of knowledge. The described method, together with the statistical control data, is used for other social and economic objects research.

The successful model testing in the form of artificial neural network model of Chernivtsi region static parameters has revealed the peculiarities of its interaction with European neighbors. In particular, for the first time we have defined their contribution to the increase of some social and economic indices on the period 20052015 , that cannot be explained by other methods, such as correlation and regressive analysis. Applied use of the isolated investigation idea of the complex meso level systems together with the technology of data mining allows solving many actual tasks nominated by the regional administration practical workers.
\end{abstract}

Index Terms-System approach, regional social and economic system, data mining, neural network.

\section{INTRODUCTION}

Operating a complex system is possible only when we fully understand its inner nature. That is why an effective administrative mechanism is closely connected with finding the objective regularities that occur in the abovementioned systems. As the result of many reasons, it is not always possible to set cause-effect interdependences of their inner constituents.

Thus the extent of social and economic systems has a direct influence on solving the problems. For the social and economic systems of national level we have developed a large amount of their behavior concepts, generally recognized models of different types and formalized notions. The explanation is the inertness of macro systems and lesser effects (when comparing with the regional one) on their state of the environment, that makes such systems, to some extent, closed in some periods of time and more easy for investigation.

When studying a region as a complex spatial and dynamic open system [1], we should mention that its lesser extent, subsystem belonging to the systems of higher national level, makes the problem of the environmental influence the matter of principle for researchers and practitioners. We speak not only about the system and environment division, but also about revealing the regularities that are peculiar for the region as a separate system. In particular, the regularities of the administrative processes, that lead to changing of its social and economic subsystem statuses are generated and are possible only because of the local administrative subjects activities. It is important to find out and support the processes that happen due to the interaction of regional system elements and not because of the national and global influence.

The tendencies of the frontier European Union regions integration demand the estimation of their influence on the inner parameters status. Defining its real extent and tendencies in its pure form, together with neglecting other factors of macro- and meso- levels, is topical.

The rest of the paper is organized as follows. Section 2 briefly reviews the related works of system investigation of close and open systems. Section 3 describes the approaches of closed systems model formalization. The description of the method of Chernivtsi region formalization is provided in Section 4. Section 5 reflects the selection of statistic parameters of Chernivtsi social and economic system. In Sections 6 and 7 we have stated the description of the system neural network model and its realization on the basis of the selected statistic data. In Section 8 we analyze the obtained results and draw the conclusions. 


\section{RELATED WORK}

System approach to the perception of different environmental phenomena became widely spread in the $\mathrm{XX}$ century. System understanding of a problematic object starts with the system perception of the object under investigation that corresponds to the problem, and the matter of fact is to highlight the two essences: system (internal environment) and external environment. Certainly, when we talk about descriptive, verbal problems, the mentioned above process demands from the researchers using more complicated approaches and methodical skills.

Detailing of external and internal environment is closely connected with the notion of open system that was firstly used in Biology by L. Bertalanphy [2]. It is typical for such system that material, energy and information are always putting in and leading out. Taking into account the mentioned above H. Hacken [3] offers to study the closed system as a case of an open one that has intersected energy flows on the input as well as on the output stage (Fig. 1 and Fig. 2). In other words, closed system is a system in which there is no free energy exchange with external environment subjects and influence of these subjects on such system is practically zero.

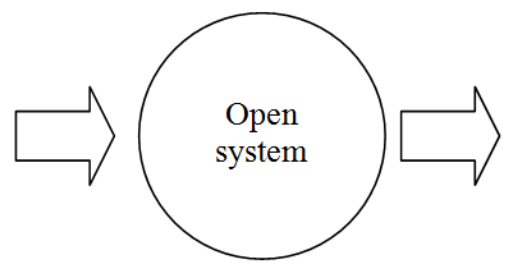

Fig.1. Approach to studying open system [3]

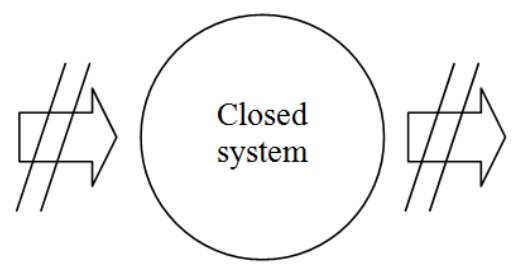

Fig.2. Approach to studying closed system [3]

Another approach, when interpreting the closed systems, is the assertion that such systems are the systems adequately modeled by statistical methods using, for example, regression techniques $[4,5]$. In economic geography, closed systems are the formations, the structure of which does not change within a certain period of time [6].

We should mention that due to the investigation of the conditionally closed systems, exact natural sciences have gained their progressive achievements. So, in engineering and physics, it is rather easy to neglect the influence of external environmental factors. Example: the motion description of a material point, ignoring air resistance in the laws of Newton, etc. The abovementioned led to a huge amount of linear, determined regularities of problem objects in natural sciences and their wide use in the practical activity of humanity.

In the case of regional systems, which are open and have at least one social and economic subsystem, their study as "isolated" objects are rather complicated and, as many scientists claim - practically impossible. Open systems are characterized by being statistically incompletely described [4]. Existing statements as to the physical and social systems fundamental differences that lay in the impossibility of quantitative analysis of the latter, in particular, using of linear programming, queuing theory, regression analysis, scheduling algorithms, and Monte Carlo simulation are not able to capture the dynamic nature of important processes in the real world [7].

Thus, the attempts to take into account the factors of internal and external environment caused the development of the nonlinear and synergy theories. On this stage the researchers accepted that if it is impossible to put aside the environmental influence, then the problem object should be studied, as an evolutional formation that is able in its stochastic nature to self development and producing the bifurcation points in the dynamics of states. Mandatory introduction of goals in the system development (including regional social and economic systems) led to appearing the system characteristics models that allow estimation the influence of the possible changes in the environment (mostly macroeconomic tendencies) on the main aspects of the regional planning. As follows, modern system investigation of the regional objects, working out their models and main concepts takes place mostly within the paradigm of the impossibility to "isolate" the processes that occur in social and economic subsystems from the processes in the environment, in order to study and investigate them independently.

Sometimes we speak about the existence of closed and open subsystems within one system, where components are considered to be closed when they are analytically well-described as well as their interconnections are [8]. There are also the present attempts to describe sequential models which are simpler closed systems and can present the social interaction [9]. The literature in the social sciences reveals different definitions of "closed" systems (and their "canned" models) that is one in which the causes creating the behavior of interest lie within the system [7].

Though studying the system as a closed one demands understanding of the role of external factors and the ways in which they might influence decisions and events at different stages [9]. That is to say we need a new method of severance or isolating their influence.

\section{METHODS AND THE MODEL}

Taking into account the above-mentioned in the article we have suggested and substantiated the hypothesis of the model decomposition of the complex systems external environment influences with the aim of describing the functioning of heir inner mechanisms.

Firstly, we should define the descriptive parameters of 
the regional social and economic system and the external environment. Here we want to mention that the contrast "system-environment" is the relation between objects and not between notions. The environment contrasts the system not as something different from it but as another system $[2,10]$. Thereby, it is rather acceptable to define the identical parameters of the two systems: the problem object and the external environment. In our case, we correlate, to such parameters, the dynamic rows of the regional statistic data $X_{i}(t)$ for the first system and the national statistical data and bordering regions statistic data $Y_{j}(t)$ for the second one (Fig. 3, where indices $i$ and $j$ - are the conditional denotation for the type of a statistic parameter). Today in many countries there has been conducted a considerable amount of qualitative statistic observations of the objects on different levels and that's the reason why the parametric description of such systems is not a complicated task.

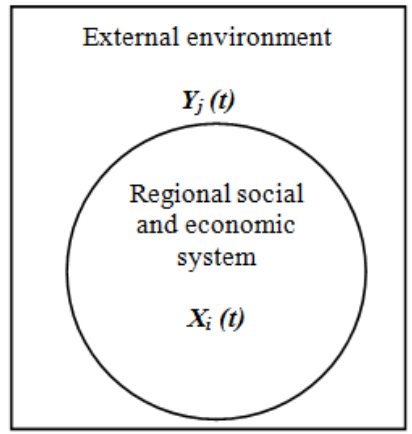

Fig.3. Parametric description of a regional social and economic system and its external

Defining the system parameters allows passing to the building of its formalized model. Considering the adopted system description parameters, we should talk about the discrete formalization type owing to the discrete characteristics of the statistic observation results. Besides, the numerical type of the system parameters is determined as the key one - the mathematic and statistic approaches of its modeling.

The main idea of the regional social and economic system is the mechanisms description of its functioning $S(t)$ integrally with the external environment:

$$
S(t)=F\left\{X_{i}(t) ; Y_{j}(t)\right\}
$$

In the case of the successful functional description $F$ of such system the acceptable variant of "cutting off" the external environment influences on its processes, as the authors suggest, should be studying the dynamic behavior of the state changing when the parameters of the external environment are invariable ( $Y_{j}$ is constant). Accordingly the model allows determining the effect of the external environment limited influence (as a separate system) on the object under investigation. Under such conditions, the outgoing result of the work of the model
(1) will be supplied only by inner regularities of its functioning. Determining the latter is very important within the sphere of regional administration, as it allows finding answers to some urgent questions: defining the extent of the regional objects administration undertaken by the actions of the local authorities (and not by combining them with the centralized administrative influences); separating the behavior of the regional systems caused by intra regional interactions (and not by macro tendencies influences); revealing the self organization tendencies in the regional indices dynamics; distinction the influence of some certain bordering neighbors on the dynamics of social and economic region development, etc.

\section{MODEL DEVELOPMENT}

Formalization of the model (1) is connected with a number of peculiarities. So, the exactness of the regional processes under study description will be directly proportional to the number of regional social and economic system parameters $(i)$, external environment $(j)$ and time points that will describe the discrete dynamics of the states in some particular time horizon. Therefore we deal with the optimization task of taking into account the maximum possible number of replaceable models that may be mathematically described, considering the restrictions of modern mathematics and computer technology development. On the other hand, the built model, as well as the results of its work, should be open for the interpretation of a user (administrator) and serve as a functional system element in order to support his/ her decisions.

Taking into account the above-mentioned, the authors find out one of the formalization approaches of the suggested model in using the technology - Data Mining. In particular, when studying Ukrainian regional social and economic systems, we have suggested and approbated the following technological succession in five stages (Fig. 4).

The process of functioning and formation of economic and social relations of the native region undergoes the influence of numerous endo- and exogenous factors. We should correlate the influences of the national social and economic system and the influences of the social and economic neighboring countries systems, which are better seen when we study bordering regions to the most powerful influence of the latter. The above-mentioned complicates greatly the process of regional administration. Working out the strategies of the regional development when building the regional development trajectory makes it impossible to estimate adequately the separated influences of the mentioned exogenous factors, and, as follows, to introduce measures in coordinating the positive influences and counteract the negative ones. 


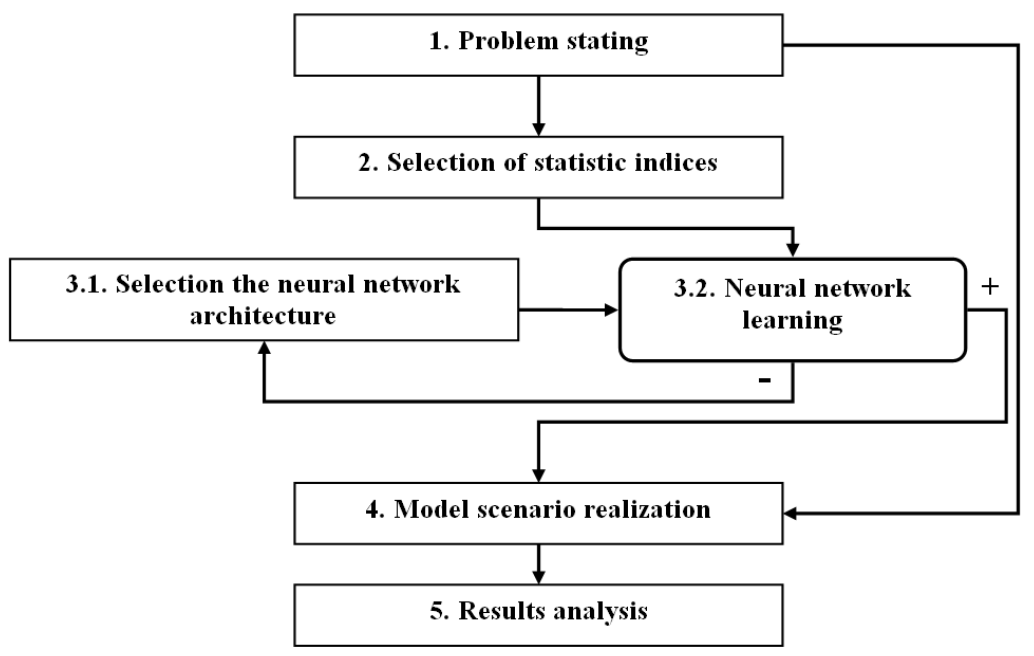

Fig.4. Model building algorithm.

Alternative means of the correlative analysis cannot integrally, quantitatively and differentially give the answer to what the influence of the defined factor is in the dynamics of the social and economic system indices. Though, the process analysis of the strategic region management of the regions in the Carpathian area reveals the problem of taking into account the influence of bordering neighbors social and economic systems, which is especially important within the scope of the Paretto effect and the prospective of coordinated synergetic development.

The object of investigation of this paper is Chernivtsi region, as the constituent part of regional system formed by the Carpathian area, situated to the west of Ukraine (Fig. 5). Geographical position of the area is rather specific and is characterized by a number of positive and negative features that is principally an ordinary phenomenon for every social and economic region of the state. The Carpathian area is situated near the centre of Europe, on the border of its Central and Eastern parts.

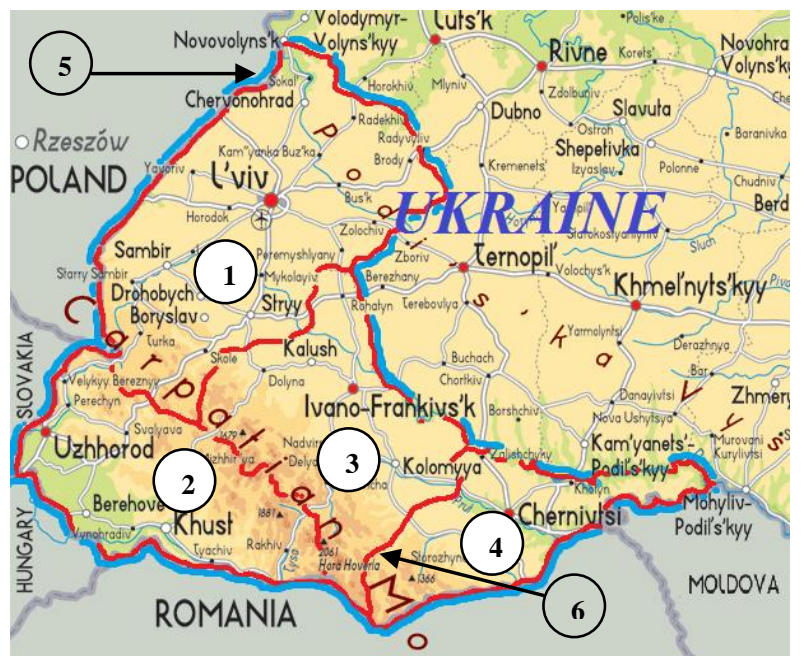

Fig.5. The Ukrainian's part of the Carpathian area

(1 - Lviv region; 2 - Transcarpathian region; 3 - Ivano-Frankivsk region; 4 - Chernivtsi region; 5 - Borders of the Ukrainian's part of the Carpathian area; 6 - Borders of regions)
When solving the problem we have defined the necessity of separation and estimation the influence (positive or negative) of the social and economic systems of the closer European neighbors: Poland, Moldova, Romania and the dynamics of the purpose-oriented parameters of Chernivtsi region.

\section{DATA SET USED}

Solving the problems of parameterization foresaw the selection of some numerical regional statistics data, National counting system, World Bank statistic data, that reflect the behavior and functioning peculiarities of the problem object more precisely.

The main criteria when selecting the indices were: description of all the issues in the National counting system; accessibility of statistic data for Ukrainian regions on the period 2005-2016; avoiding doubling the indices that have similar influence.

The necessity to take into consideration the national and regional systems is conditioned by the understanding that national and international processes have sharply differential effects on sectors and regions [11]. Furthermore, without a consideration of interregional and national-regional links, there is no consistency guarantee for a model of a spatial system as a whole [12].

Within the data parameterization of the State Statistics Service (http://www.ukrstat.gov.ua/) we have chosen 14 national/ regional indices, that by their nature completely allow estimating the social and economic development, i.e.:

- GRP (GDP) per capita, UAH $\left(R G_{l} / U A_{n l}\right.$ - here still is used by the authors to denote the index);

- Average salary, $\mathrm{UAH}\left(R G_{2} / U A_{n 2}\right)$;

- Consumer Price Index $\left(R G_{3} / U A_{n 3}\right)$;

- Export, mln. USD $\left(R G_{4} / U A_{n 4}\right)$;

- Industrial production index $\left(R G_{5} / U A_{n 5}\right)$;

- Agricultural production index $\left(R G_{6} / U A_{n 6}\right)$;

- Direct investments, mln. USD $\left(R G_{7} / U A_{n 7}\right)$; 
- Capital investments mln. UAH $\left(R G_{8} / U A_{n 8}\right)$

- Index of completed construction work volume $\left(R G_{9} / U A_{n 9}\right)$;

- Transport of goods by road, mln. t. $\left(R G_{10} / U A_{n 10}\right)$;

- Passenger transportation by road, mln. pas. $\left(R G_{11} / U A_{n 11}\right)$;

- Wholesale trade, mln. UAH $\left(R G_{12} / U A_{n 12}\right)$;

- Volume of retail turnover of enterprises (legal entities) mln. UAH ( $\left.R G_{13} / U A_{n 13}\right)$;

- The unemployment among working-age population $\left(R G_{14} / U A_{n 14}\right)$.

To parameterize the system of bordering countries, and in addition to the national system parameterization, we have used the indices of the World Bank (http://databank.worldbank.org/data/home.aspx) that form the conception about the level of their development and make it possible to estimate the level of their influence on the studied region. Among the most significant indices we have chosen:

- GDP per capita, USD $\left(C N_{l} / U A_{w l}\right)$;

- Export in \% as to GDP $\left(\mathrm{CN}_{2} / U A_{w 2}\right)$;

- Import in \% as to GDP $\left(\mathrm{CN}_{3} / U A_{w 3}\right)$;

- Consumer Price Index, in \% $\left(C N_{4} / U A_{w 4}\right)$;

- Number of Internet users per 100 inhabitants $\left(C N_{5} / U A_{w 5}\right)$;

- Unemployment rate, in \% $\left(C N_{\sigma} / U A_{w 6}\right)$;
- Added value of agricultural production in $\%$ as to $\operatorname{GDP}\left(\mathrm{CN}_{7} / U A_{w 7}\right)$;

- Debt of the central government in \% as to GDP $\left(C N_{8} / U A_{w 8}\right)$.

\section{BUILDING ANN MODEL}

The potential of using ANN modeling of complex processes and systems is acknowledged by numerous successful objects under investigation in medicine, biology, sociology, economics, etc. The basis of the success was the connectionist architecture of ANN and its universal approximation ability that emerges from the interactions among its neurons. Taken separately, a single neuron has no real abilities; it is capable only of performing extremely simple operations such as addition and multiplication $[13,14]$.

When forming the architecture of a neural network we have chosen the following parametric inputs: $n$ (is equal 8) statistic parameters of external environment (according to the World Bank data) and $m$ (is equal 14) statistic parameters of external environment (according to the data of the National Accounts Systems), that are responsible for the state of Ukrainian social and economic system $U A_{1}, . ., U A_{n}$; $k$ (is equal 14) parameters, that describe the state of the regional social and economic system $R G_{l}^{\text {out }}, . ., R G_{k}^{\text {out }}$ (Fig. 6.).

\section{Inputs}

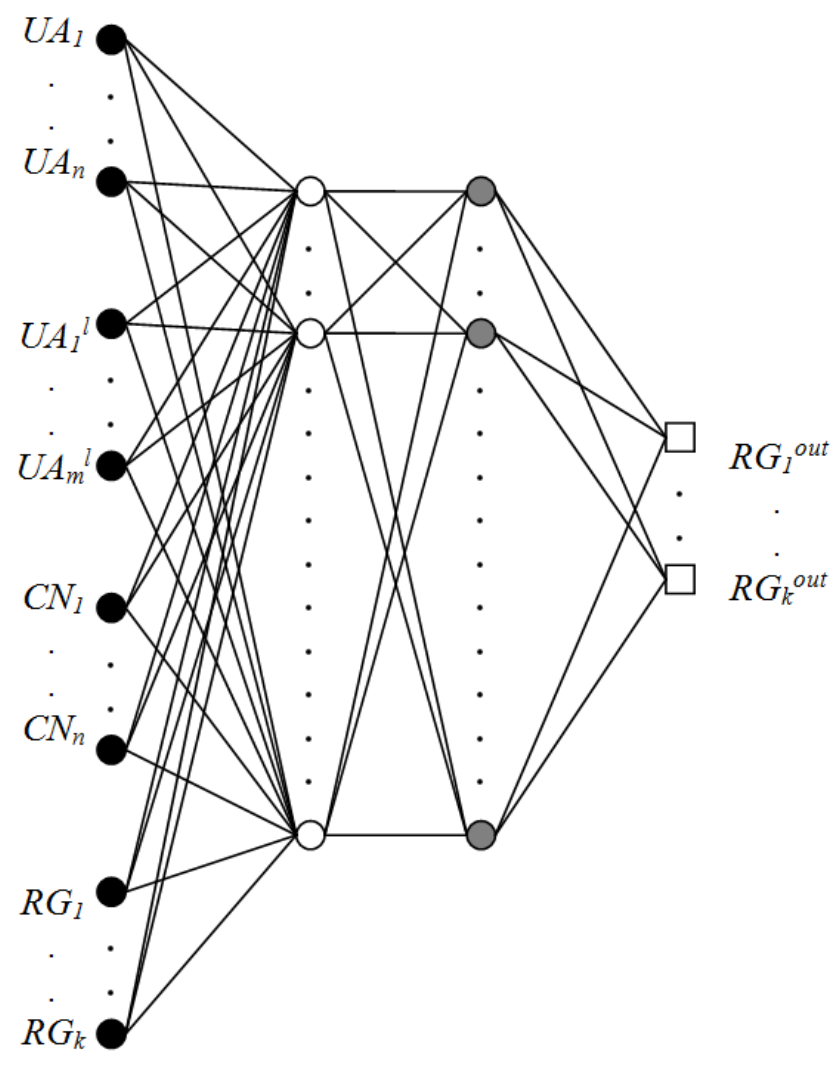

Outputs

input layer

hidden layers

output layer

Fig.6. Neural network model. 
As the applied environment for neural network building, we have chosen the academic version of the program Deductor Studio Lite 5.1 released by Base Group Labs. Taking into account the fact that today there are no generally accepted methods of neural networks architecture formation, the given process is to great extent subjective and dependent on the skills of a researcher as well as on the given task conditions. So, in the process of architecture selection, we have tested more than 10 types with different number of hidden layers and neurons to reach the acceptable exactness of the analysis. The final architecture of the built neural network consists of 44 inputs, 2 hidden layers, that have 44 and 14 neurons accordingly and 14 outputs. The limit number of hidden elements is agreed with the investigation approach [15].

The organization of the learning procedure (training) of a neural network was based on the assumption, that the future $(t+1)$ output parameters state will be formed by the present input state $(t)$.

With the aim of better model learning we have increased 11 times (taking into account 12 months' periods between years) the number of first data rows by linear interpolation of points between years 2005-2015 for all indices. That's why, the neural network was learning on the basis of 8880 data points. The data were set in an explicit form of statistical indices and undergone preprocessing by internal tools of Deductor Studio, in particular specific transformations. When selecting the architecture of ANN model the entries were divided into learning and test sets in the proportion 95 and 5 per cent accordingly. The final model was verified by the test set of $30 \%$ from the entries. We used sigmoid as an activation function of neurons. As the learning algorithm there was used the method of back propagation [16]. The learning error for the whole data set was $0,5-$ $15 \%$. In the learning process we have identified $100 \%$ of test and learning selection that is the evidence of the satisfactory chosen neural network and confirms the adequacy of the model.

\section{REALIZATION OF THE MODEL SCENARIO}

Realization of the model scenario foresees using the neural network learned by the iteration selection of neurons weight coefficients according to the task set.

On the neural network inputs we have placed numeric rows of input parameters formed beforehand and adapted to the problem task. In the case of input indices of regional social and economic system and investigated factor of a bordering neighbor, the data were given with an obvious statistic representation for the whole retrospective investigation time. Input parameters that defined the influence of the external environment were model determined as constants for the whole span of time in model investigation and in our case were equal to their initial statistic meaning of the starting time point of the investigation (Fig. 7.).

As follows, in the conditions of the model scenario realization for the system under study, we have managed to differentiate the influences of the external environment: in our case - macroeconomic influences of the national social and economic system.

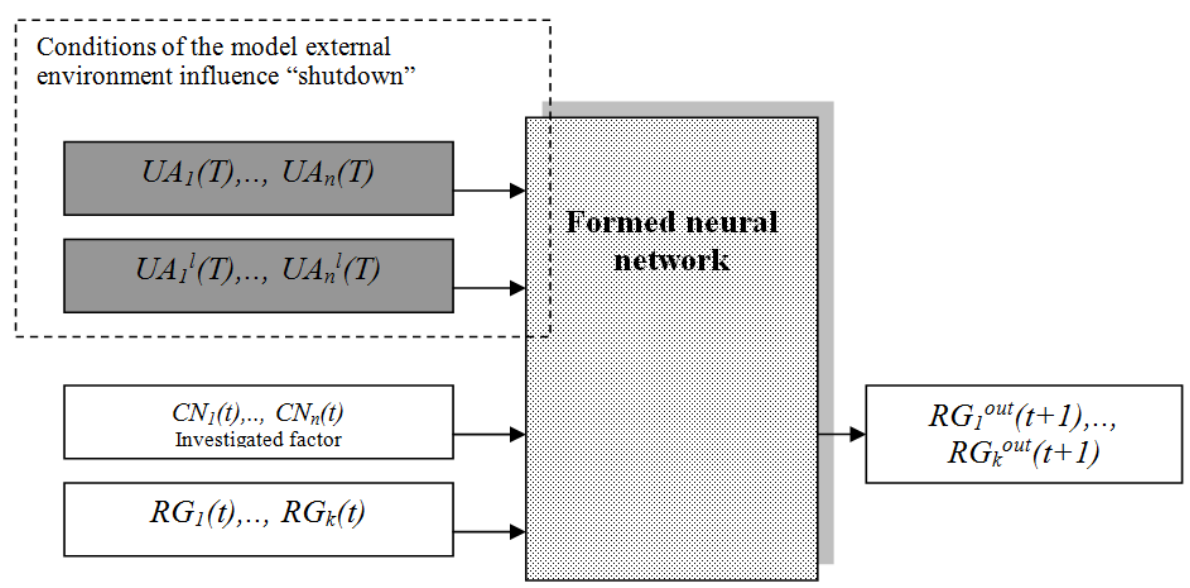

Fig.7. Model scenario realization schemes

\section{RESULTS ANALYSIS}

Model indices of the GRP dynamics in Chernivtsi region (Fig. 8) formed under the influence of European neighbors partially replicate some basic statistics dependency peculiarities $\left(R G_{l}\right)$, though, as to the absolute value, they are substantially lesser for all the time points of the analysis (2005-2015).

As we see in Fig. 8, the biggest influence on the GRP regional dynamics is made by social and economic systems of Romania (ROM) and Poland (POL). Notwithstanding the geographical distance of Poland, its influence on Chernivtsi region GRP formation is significant because of high level of integration policy in season employment and educational services. In the period 2014-2015 the influence of Romania began prevailing over the one of Poland due to the export increase of regional raw materials resources and activation of project collaboration.

With the aim of conducting the comparative analysis 
of the above-mentioned countries influence on Chernivtsi region parameter dynamics, there has been implemented linear interpolation of calculated dependences. As a previous comparative quantity, we have chosen the quadrant depression of obtained linear trends to the axis abscissa.

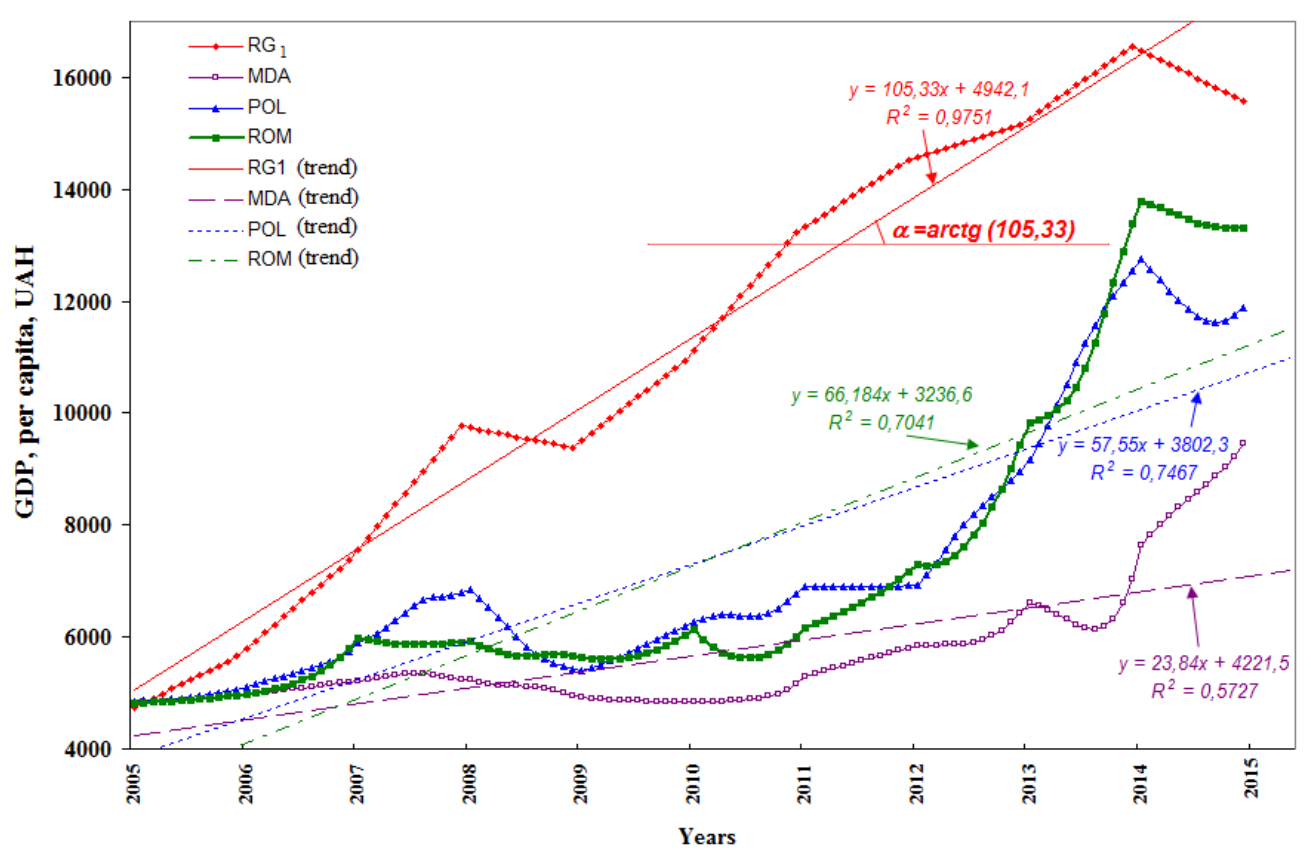

Fig.8. Influence of European neighbors on the formation of Chernivtsi region GRP

As we see from the comparative analysis results of the quadrant depression of obtained linear trends to the axis abscissa (Fig. 9 and Fig. 10) the influence of European neighbors on social and economic indices dynamics in Chernivtsi region (on the period 2005-2015) is differential in terms of the country and the index nature.

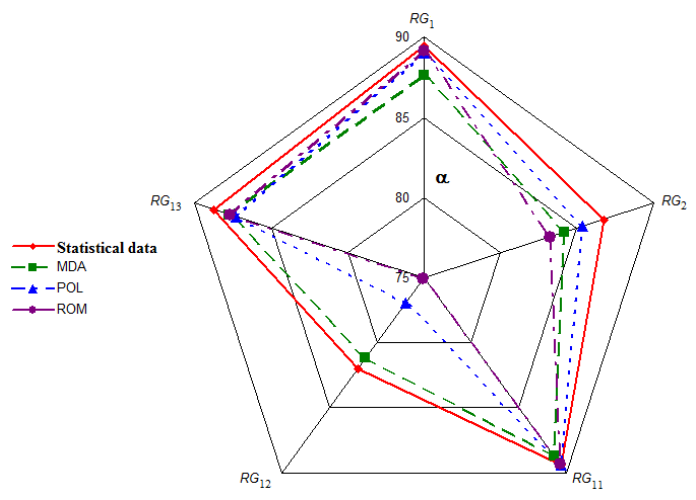

Fig.9. Influence of European neighbors on the dynamics of $\mathrm{RG}_{1}, \mathrm{RG}_{2}$, $\mathrm{RG}_{11}, \mathrm{RG}_{12}, \mathrm{RG}_{13}$ indices of Chernivtsi region (on the period 2005-2015)

So we should undergo the obtained model results further analysis because of the influence of neighboring countries on the indices increase "Consumer prices index" $\left(R G_{3}\right)$, “Export, mln. USD” $\left(R G_{4}\right)$, "Industrial goods index" $\left(R G_{5}\right)$, "Capital investments, mln. UAH" (was not included in Fig. 9. and Fig. 10: $\alpha_{\text {stat. }}$ (is equal $58^{\circ}$ ), $\alpha_{\mathrm{MDA}}$ (is equal $87^{\circ}$ ), $\alpha_{\mathrm{POL}}$ (is equal $85^{\circ}$ ), $\alpha_{\mathrm{ROM}}$ (is equal $83^{\circ}$ ). The conducted calculations confirm that the influence of national social and economic system on the stated indices of Chernivtsi region has restraining character and to improve the situation in future we should take into account the potential of border interaction with Moldova, Romania and Poland.

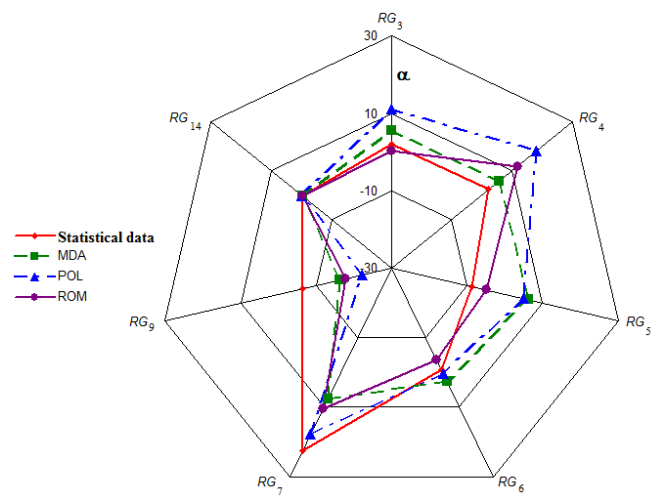

Fig.10. Influence of European neighbors on the dynamics of $\mathrm{RG}_{3}, \mathrm{RG}_{4}$, $\mathrm{RG}_{5}, \mathrm{RG}_{6}, \mathrm{RG}_{7}, \mathrm{RG}_{9}, \mathrm{RG}_{14}$ indices of Chernivtsi region (on the period 2005-2015)

The influence of border countries on the fixed level of unemployment among the working population $\left(R G_{14}\right)$ in Chernivtsi region improves its restraining character. In the case of employment system crisis the level of unemployment remains the same due to the unregistered employment of the region's inhabitants abroad.

The level of retail enterprises turnover $\left(R G_{13}\right)$ in Chernivtsi region is formed mostly by the influence of neighboring countries that improves a high import dependency of the region's goods market and needs implementing reactions. 


\section{CONCLUSION, LIMITATIONS AND FUTURE WORK}

In the present paper we have offered the method of isolating the influence of some outer environmental factors on social and economic system of the region. The above stated allowed concentrating on some aspects of its functioning, identically to the system analysis of technical systems.

The successful model testing in the form of ANN model of Chernivtsi region static parameters has revealed the peculiarities of its interaction with European neighbors. In particular, for the first time we have defined their contribution to the increase of some social and economic indices on the period 2005-2015 that cannot be explained by other methods, such as correlation and regressive analysis.

Applied use of the isolated investigation idea of the complex meso level systems together with the technology of data mining allows solving many actual tasks nominated by the regional administration practical workers.

The prospective of further model realization is the efficiency estimation of local authorities influence on regional processes, studying the processes of regional interaction and revealing the homeostatic system properties of regional systems.

\section{REFERENCES}

[1] Hudec Oto, Nataša Urbančíková, "Systemic approach to regional planning" // 3rd Central European Conference in Regional Science CERS - 2009. - P. 357-368, 2009.

[2] Bertalanffy L., "General system theory: foundations, development, applications". - N.Y.: G. Braziller, 1969. 289 p., 1969.

[3] Herman Haken, "Information and Self-Organization: A Macroscopic Approach to Complex Systems", (3rd enlarged ed.). - 2006. - P. 262, 2006.

[4] U. Beyer and F. Smieja, "Data exploration with reflective adaptive models," Computational Statistics Data Analysis, vol. 22, pp. 193-211, 1996.

[5] Samuel E., Knockaert L. and Dhaene T., "Multipoint Model Order Reduction Using Reflective Exploration". In Book: Scientific Computing in Electrical Engineering. - pp.1-2, 2016.

[6] MacKinnon, D., Cumbers A.; Pike A., Birch K., and McMaster, R., "Evolution in economic geography: Institutions, political economy, and adaptation". Economic Geography 85:129-50, 2009.

[7] Forrester, J. W., "System dynamics, systems thinking, and soft OR". System Dynamics Review, 10, 245-256, 1994.

[8] Mole K., "Systems theory and the common-sense view of advisers", Journal of Small Business and Enterprise Development, Vol. 11 No. 1, pp. 114-20, 2004.

[9] Ye, L., and Wu, A. M., "Urbanization, Land Development, and Land Financing: Evidence from Chinese Cities". Journal of Urban Affairs, 36(sup1), 354368, 2014.

[10] Liu, S., Yang Y., Xie N., and Forrest J., "New progress of Grey System Theory in the new millennium". Grey Systems: Theory and Application, 6(1), 2-31, 2016.

[11] Zhang B., Qiao H., Chen Z. M., and Chen B., "Growth in embodied energy transfers via China's domestic trade:
Evidence from multi-regional input-output analysis". Applied Energy, 184, 1093-1105, 2016.

[12] Flegg A. T., and Tohmo T., "Estimating Regional Input Coefficients and Multipliers: The Use of FLQ is Not a Gamble". Regional Studies, 50(2), 310-325, 2014.

[13] Basse R. M., Omrani H., Charif O., Gerber P., and Bódis K., "Land use changes modelling using advanced methods: cellular automata and artificial neural networks. The spatial and explicit representation of land cover dynamics at the cross-border region scale". Applied Geography, 53, 160-171, 2014.

[14] Bersini H. De., "l'intelligence humaine_a l'intelligence artificielle”. Ellipses Editions, 2006.

[15] Nielsen R. H., "Kolmogorov's Mapping Neural Network Existence Theorem". // Proceedings of the IEEE First International Conference on Neural Networks. - San Diego. - 1987. - P. 11-13, 1987.

[16] Caruana S., Lawrence, and L. Giles, "Overtting in neural nets: Backpropagation, conjugate gradient, and early stopping”. In Advances of Neural Information Processing Systems, volume 13, pages 402-408, 2001.

\section{Authors' Profiles}

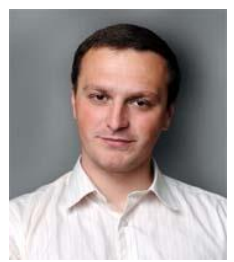

Yurii Koroliuk is the professor of Department of Economic Cybernetics and International Economic Relations, ChITE KNUTE, Chernivtsi, Ukraine. $\mathrm{He}$ graduated from Yuriy Fedkovych Chernivtsi National University in 2001. In 2004 Koroliuk received Ph.D. in Physics and Mathematics, in 2012 received Doctor Science of Public Administration. He has published over 100 articles in both reputable national and international journals and conferences. The area of scientific interests is the problem: the study of complex systems; management of socio-economic development of regions; applied system analysis of economic and social systems; Data Mining and ANN technology.

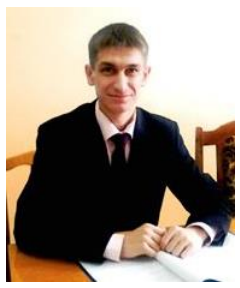

Valentin Hryhorenko is manager of the Ukrainian Leadership Academy, Lviv, Ukraine. He graduated from Chernivtsi Institute of Trade and Economics KNUTE and received Master degree in Public Finance. He has published over 25 articles in both reputable national and international journals and conferences. The area of scientific interests is the problem: the study of complex systems; management of socio-economic development of regions; management of financial capacity.

How to cite this paper: Yurii Koroliuk, Valentyn Hryhorenko, "ANN Model of Border Regions Development: Approach of Closed Systems", International Journal of Intelligent Systems and Applications(IJISA), Vol.11, No.9, pp.1-8, 2019. DOI: 10.5815/ijisa.2019.09.01 